\title{
Ambientes virtuais de aprendizagem e o modelo TPACK: relato de experiência de oferta de cursos em diferentes plataformas de educação a distância
}

\author{
Ricardo Marques Nicolau', Vanda Arantes Araújo ${ }^{2}$, Edson Moura da Silva ${ }^{3}$ \\ ${ }^{1}$ Programa de Pós-Gradução em Educação - Pontifícia Universidade Católica de Minas \\ Gerais (PUC MINAS) - 30.535-901 - Belo Horizonte - MG - Brasil \\ ${ }^{2}$ Universidade do Estado de Minas Gerais - Faculdade de Políticas Públicas "Tancredo \\ Neves" - 31.130-150 - Belo Horizonte - MG - Brasil \\ ${ }^{3}$ Programa de Pós-Gradução em Educação - Pontifícia Universidade Católica de Minas \\ Gerais (PUC MINAS) - 30.535-901 - Belo Horizonte - MG - Brasil \\ ricnic.br@gmail.com, vanda.araujo@uemg.br, edsonmoura.senac@gmail.com
}

\begin{abstract}
This article presents a reflection on challenges and possibilities of Distance Education from the online course management experience in three different e-learning platforms - Docebo, eFront and Ilias -, carried out by groups of masters and doctoral students, in 2014. The data were obtained by participant observation during the course and documentary research of discipline completion reports drawn up by postgraduate students. The results reveal that the online courses presented differences in the articulation of technological, pedagogical and content knowledgements, defined in TPACK model.
\end{abstract}

Resumo. O presente artigo traz uma reflexão sobre desafios e possibilidades da Educação a Distância a partir da experiência de gestão de cursos online em três diferentes plataformas de ensino a distância - Docebo, eFront e Ilias -, realizada por grupos de mestrandos e doutorandos em disciplina ministrada em programa de pós-graduação no ano de 2014. Os dados foram obtidos por observação participante durante o desenvolvimento do curso e pesquisa documental dos relatórios de conclusão da disciplina elaborados pelos pósgraduandos. Os resultados revelam que os cursos online apresentaram diferentes articulações dos conhecimentos tecnológico, pedagógico e do conteúdo definido no modelo TPACK.

\section{Introdução}

A expansão das tecnologias digitais de informação e comunicação (TDIC) a partir dos anos 1990 com a criação da Internet, a regulamentação da modalidade de ensino a distância (Lei de Diretrizes e Bases nº 9.394 de 1996; Decreto n ${ }^{\circ} 5.622$ de 2005) e a sua expansão no sistema educacional brasileiro, pelo Decreto $n^{\circ} 5.800$ de 2006 que cria a Universidade Aberta do Brasil (UAB), chamou a atenção de pesquisadores para investigarem limites e possibilidades dessa modalidade de ensino.

No Brasil, a definição oficial da Educação a Distância é recente, dada pelo Decreto $\mathrm{n}^{\circ}$ 5.622, de 19 de dezembro de 2005. Mostrando que ainda há diferentes visões sobre a 
trajetória da EaD, Vilaça (2010) cita dois estudos. O primeiro deles, Maia e Mattar (2007), subdividem a história da $\mathrm{EaD}$ em três gerações: i) ensino por correspondência; ii) rádio e TV; iii) EaD online. O outro, Moore e Kearsley (2008), entendem que seria mais adequada a divisão histórica em cinco gerações: i) ensino por correspondência; ii) transmissão por rádio e TV; iii) Universidades Abertas; iv) teleconferência; v) Internet/web. Sem discutir se a atual geração da $\mathrm{EaD}$ é a terceira ou quinta, o que fugiria ao escopo desse texto, é fato que a $\mathrm{EaD}$, ao longo dos anos, vem se apropriando de tecnologias disponíveis e sua regulamentação ratifica-a como modalidade de ensino no sistema educacional brasileiro.

Em 2004, o Ministério da Educação e Cultura (MEC) fortaleceu essa modalidade de ensino ao implantar diversos programas para a formação inicial e continuada de professores da rede pública via $\mathrm{EaD}$. Em 2007, o Decreto $\mathrm{n}^{\circ} 6.303 / 2007$ alterou dispositivos do Decreto n 5.622 que regulamenta a EaD na LDB. Em 2012, o MEC anunciou plano para triplicar o número de matrículas em cursos públicos de $\mathrm{EaD}$ em dois anos, passando de 210 mil alunos naquele ano para 600 mil alunos, por meio da UAB.

A fim de atender a essa demanda, as IES estão inserindo disciplinas que tratam da temática do ensino a distância em seus currículos, concordando com Maia e Mattar (2007) e Moore e Kearsley (2008), citados por Vilaça (2010), quando definem que a geração atual [seja ela a terceira ou quinta] está conectada em rede pela Internet. Os ambientes virtuais de aprendizagem (AVA) passaram, então, a ser utilizados por várias dessas IES.

Os AVA são plataformas baseadas na Internet com as quais se pode oferecer cursos na modalidade a distância em dois formatos principais: online ou e-learninge blended learning, conhecido no Brasil como Ensino Semipresencial. Nos dois formatos de curso a distância [online e blended], a oferta de cursos com qualidade passa pela articulação de conhecimentos pedagógicos, conhecimentos relativos ao conteúdo a ser aprendido e conhecimentos sobre tecnologia(s) que pode $(\mathrm{m})$ mediar o ensino e a aprendizagem.

Em função da disponibilidade de tecnologia, da regulamentação, dos interesses públicos e privados, a $\mathrm{EaD}$ é cada vez mais utilizada, mesmo com as dificuldades apresentadas no cenário brasileiro por Alves (2011). Não se pode perder de vista a possibilidade de democratização da educação oferecida por esta modalidade de ensino e a necessidade de oferta que alcance efetiva inclusão digital. Lembrando que esta inclusão vai além da simples presença de tecnologia geradora de mão de obra para o mercado; é fundamental educar o sujeito para viver neste tempo (Silva, 2010).

Assim sendo, para dar conta de seu papel social, qualquer modalidade de educação [presencial ou a distância] precisa integrar tecnologia e currículo. Esta demanda tem atraído a atenção de pesquisadores interessados em compreender como esse processo se dá e que caminho(s) podem conduzir a educação rumo ao que se espera dela. Esse trabalho de investigação insere-se nesta linha de pesquisa.

O objetivo da pesquisa foi investigar um grupo de estudantes de pós-graduação em educação, durante o curso de uma disciplina na modalidade a distância entre os meses de março e julho de 2014, com o intuito de verificar estratégias utilizadas para a oferta de cursos a distância em AVA e identificar em que medida os estudantes se apropriaram das plataformas no desenvolvimento do trabalho e de como articularam os conhecimentos tecnológicos, pedagógicos e de conteúdo. 
A proposta da disciplina foi disseminar o conhecimento de plataformas AVA para o corpo discente e um de seus objetivos era permitir o aprendizado pela experimentação do processo de oferta de cursos a distância, desde a concepção até a avaliação. Para isso, a turma foi dividida em cinco grupos e cada grupo ficou responsável por pesquisar, descobrir as potencialidades, conhecer e testar os recursos, bem como a interface de diferentes plataformas: ATutor, Claroline, Docebo, eFront e Ilias.

Cada grupo ficou também responsável por oferecer um curso através da plataforma e pelos respectivos conteúdos: Avaliação na EaD; Material instrucional na $\mathrm{EaD}$; A docência na $\mathrm{EaD}$; Tutoria na $\mathrm{EaD}$, e; Gestão na EaD. Dessa forma, cada componente do grupo participou como gestor, autor e tutor na sua respectiva plataforma e também como aluno das outras quatro plataformas. Destes cinco grupos, três fizeram parte do escopo da pesquisa. A restrição a três das cinco plataformas se deu pelo fato de que cada um dos autores deste artigo foi gestor de cada um dos grupos, o que permitiu maior acuidade na coleta e tratamento de dados. Vale destacar que os investigadores também atuaram como integrantes destes três grupos AVA, denominados: Docebo, eFront e Ilias.

Dentre as atribuições de cada grupo, destacam-se: planejar, ministrar e avaliar integralmente o curso; serem autores, com o intuito de elaborar e ministrar o conteúdo proposto para o grupo; atuar pedagogicamente, com o objetivo de facilitar a aprendizagem; fomentar o conhecimento acerca dos diversos recursos oferecidos pela "nova" plataforma. Coube a cada grupo também a responsabilidade pela função de Tutoria, seja no acompanhamento dos alunos (colegas do curso de mestrado e doutorado), dirimindo dúvidas, propondo soluções, acompanhando os fóruns e na realização das atividades avaliativas. Todos os alunos, em seus respectivos grupos, desempenharam também a função de Gestores, seja no acompanhamento geral do curso, na manutenção, resolução de acessos à plataforma e no acompanhamento das atividades previstas em cada curso.

\section{Trabalhos Relacionados}

Marinho (2006) apontou o descompasso entre tecnologia e currículo enfatizando a necessidade de sincronizá-los. Para que a integração tecnologia-currículo aconteça, numa perspectiva de aprendizagem com maior envolvimento do aluno, conforme destaca Valente (2011), vários aspectos, tais como formação docente, material didático, espaços, tempos e linguagens, deverão sofrer transformações. Nesse sentido, a EaD, o computador na sala de aula, e mais recentemente as tecnologias móveis (MARINHO, 2014) se inserem como opções que podem facilitar tal sincronismo. Não se pode perder de vista, entretanto, que, seja qual for a tecnologia mediadora, a integração curricular depende da adequada articulação de conhecimentos inerentes aos processos de ensino e de aprendizagem.

A EaD, segundo Alves (2010), apesar de sua recente regulamentação no Brasil, possui experiências que contam com comprovação histórica e que remontam ao início do séc. XX. Sua trajetória está relatada em Vilaça (2010) que cita Maia e Mattar (2007) e Moore e Kearsley (2008), os quais subdividiram esta trajetória em gerações. Cada uma dessas gerações enfrentou o desafio de integrar tecnologia e currículo.

Em seus estudos sobre a integração das TDIC ao currículo escolar, Coutinho (2011), reconhece a importância dos estudos de Shulman (1986) e apresenta o TPACK como um referencial teórico que ajudará na compreensão "da forma de como se processa 
o desenvolvimento profissional de um professor competente em TIC [ou TDIC] na sua área curricular" (COUTINHO, 2011, p.1).

O modelo TPACK decorre das ideias centrais do trabalhos de Shulman (1986) quando descreveu o modelo (PCK) - Conhecimento Pedagógico do Conteúdo. Posteriormente, com a disseminação das TDIC, os professores da Universidade de Estado de Michigan nos Estados Unidos, Punya Mishra e Matthew J. Koehler, incluíram o contex to tecnologia aos estudos de Shulman, dando origem ao modelo TPCK, atualmente TPACK (Mishra; Koehler, 2006).

\section{Metodologia e procedimentos metodológicos}

Esta investigação possui delineamento qualitativo conforme definem Bogdan e Biklen (1994) e também os estudos de Diehl e Tatim (2006, p. 52) que explicam que os estudos qualitativos têm como objetivo "descrever a complexidade de determinado problema e a interação de certas variáveis, compreender e classificar [...] o entendimento das particularidades do comportamento dos indivíduos". Esta pesquisa, portanto, em função do delineamento adotado, foi levada adiante sem se deter em técnicas estatísticas para interpretar os fenômenos e identificar significados (Brasileiro, 2013). Além disso, cabe destacar que o delineamento adotado fundamenta-se em cinco características marcantes dos estudos qualitativos apontadas por Bogdan e Biklen (1994): a) a fonte de dados é o ambiente natural e o investigador é o instrumento principal; b) a pesquisa é descritiva; c) o interesse está concentrado no processo muito mais que nos resultados ou produtos finais; d) a análise geralmente tem caráter indutivo; e) o significado tem importância capital.

Com base nos estudos de Gatti (2002), que explicam haver vários procedimentos metodológicos para o relato de experiências, neste estudo foram adotados como procedimentos metodológicos a observação participante e a pesquisa documental.

A coleta de dados, segundo os constructos teóricos apontados por Marconi; Lakatos (2009, p.167) é "a etapa em que se inicia a aplicação dos instrumentos elaborados e das técnicas selecionadas, a fim de se efetuar a coleta dos dados previstos", que para as autoras podem ser utilizados diferentes tipos, destacando a "observação" (Marconi; Lakatos; 2009, p.168), como um dos meios para se obter os dados necessários.

Considerando que os investigadores participaram ativamente das atividades da disciplina, inclusive da elaboração do relatório final, sendo portanto, ao mesmo tempo, investigadores e sujeitos da pesquisa, há, neste trabalho, a natureza descritiva-narrativa. Nas pesquisas deste tipo, de acordo com Warde (1990) apud Gatti (2002, p. 32) "a 'amostra' é o próprio autor que expõe sua 'experiência' ou 'vivência"'.

Os dados coletados foram analisados a partir do modelo TPACK proposto por Mishra e Koehler (2006). Este modelo foi utilizado como indicador da ênfase dada por cada grupo investigado ao articular cada um dos contextos que o modelo define a fim de oferecem o curso a distância em um AVA.

O ponto de partida da investigação foram as atividades da disciplina Ambientes Virtuais de Aprendizagem. Os integrantes de cada grupo receberam permissão de acesso com perfil administrador a apenas uma das cinco plataformas, a partir da qual deveriam ofertar um curso online. Coube a cada grupo garantir acesso à sua plataforma, com perfil de acesso no nível aluno, aos integrantes dos outros quatro grupos. Desse modo cada 
aluno da disciplina vivenciou os papéis de gestor, professor e tutor de um curso e foi aluno em quatro outros.

O escopo desta pesquisa restringiu a coleta de dados à três plataformas: Docebo, eFront e Ilias. Esta decisão resulta da opção de coletar dados por observação participante, não sendo possível aos pesquisadores participar simultaneamente de mais de um grupo de trabalho.

O professor responsável pela disciplina AVA encarregou-se de tarefas preliminares como solicitar a ativação inicial [instalação] das plataformas pela equipe de suporte de TI da IES, solicitar usuários com perfil administrador para os líderes dos grupos e definir prazo limite para a entrega dos relatórios finais de cada grupo.

A administração da infraestrutura de tecnologia da informação e o suporte técnico em caso de falhas no sistema operacional ou na aplicação ficou a cargo do departamento de tecnologia e informação da Instituição de Ensino Superior (IES) à qual está vinculado o programa de pós-graduação.

A observação participante foi realizada pelos investigadores que se distribuíram em três grupos de modo a vivenciar e coletar dados em cada um deles. A vantagem desse procedimento é destacada por Brasileiro (2013, p. 47) quando acrescenta que a pesquisa participante tem como vantagem a observação, pois "ocorre quando há integração do investigador com situação investigada, fazendo, de algum modo, parte do grupo".

A disciplina AVA teve como atividade de conclusão a elaboração de um relatório final. Sobre esses documentos foram aplicadas técnicas de pesquisa documental, com coleta de dados de fonte primária, de modo a extrair deles dados pertinentes à investigação.

Em seus estudos, Coutinho (2011) aponta que no desafio de integrar as TDIC ao currículo escolar [presencial ou a distância] é necessário, além da atitude dos professores, investir em uma formação adequada para o seu uso. Ao se falar em formação de professores com o objetivo do domínio da TDIC de modo que os mesmos possam incorporá-la à sua prática educativa, a autora afirma que não se encontra um referencial teórico no qual se possam embasar as práticas formativas. Nem tão pouco um referencial que auxilie os formadores na construção de "indicadores da eficácia do modelo formativo adoptado (sic)" (Coutinho, 2011, p.1). Entretanto, destaca e reconhece o modelo TPACK (Figura 1) como embasamento para auxiliar na compreensão de como o educador introduz a tecnologia em sua prática pedagógica. Knowledge.

TPACK é uma sigla em inglês de Technological Pedagogical Content

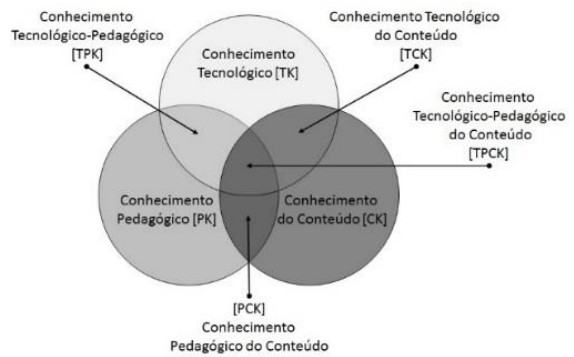

Figura 1. Modelo TPACK

Fonte: Adaptado de Mishra e Koehler, 2006. 
O modelo permite o estudo da articulação dos conhecimentos tecnológico, pedagógico e do conteúdo para a integração curricular da tecnologia. As áreas de intersecção dos três contextos TPK, TCK e PCK podem ser utilizadas como indicadores de ênfases na articulação desses conhecimentos em todas as etapas do ensino. A articulação desejada seria aquela em que os três conhecimentos são adequadamente articulados, representada pela intersecção TPCK.

Os dados foram, portanto, analisados tendo o modelo TPACK como aporte metodológico a fim de identificar a articulação que cada grupo conferiu aos três principais contextos [tecnologia, conteúdo e pedagogia] que o modelo propõe.

Para a apresentação dos resultados observados optou-se pelo relatório de experiência simples, que, segundo Brasileiro (2013), tem por objetivo apresentar e discutir os resultados obtidos.

\section{Análise dos resultados}

A primeira atividade dos grupos foi a definição de um cronograma de trabalho, o que impôs restrições ao número e tipo de atividades que poderiam ser realizadas em cada curso. $\mathrm{O}$ grupo eFront incluiu o cronograma no relatório final demonstrando forte preocupação com a organização temporal e atribuição de responsabilidades. Os registros do grupo Ilias mostram que foram discutidas datas limites e atribuídas responsabilidades com menor grau de formalização. O grupo Docebo foi o que demonstrou menor preocupação com a determinação de prazos e responsáveis. Os registros no relatório deste grupo mencionam uma divisão interna e informal de tarefas. Do ponto de vista de gestão, o grupo Docebo poderia ter problemas futuros com prazos e responsabilidades [o que se confirmou posteriormente], pois na $\mathrm{EaD}$ há menos flexibilidade para mudanças nas atividades pedagógicas após o início das mesmas. $\mathrm{O}$ grupo Ilias relatou dificuldades com prazos e responsabilidades, mas em menor escala. $\mathrm{O}$ grupo eFront não relatou tais dificuldades.

A divisão funcional foi diferente em cada grupo e revelou diferentes abordagens. O grupo Docebo, constituído majoritariamente por pedagogas e professores, enfatizou os aspectos pedagógicos. O grupo eFront constituído por duas professoras de educação básica e dois professores com formação na área tecnológica dividiu as tarefas de modo que dois integrantes se ocuparam com a plataforma e dois cuidaram da produção de material didático. $\mathrm{O}$ grupo Ilias constituído por educadores da área das ciências humanas e sociais concentrou as atividades em um dos integrantes.

Os grupos relataram indisponibilidades na conexão Internet do ambiente onde se localizavam os servidores das plataformas por falha na rede do provedor de serviços contratado pela IES, sobretudo em fins de semana. Além disso, o grupo de suporte da IES não estava devidamente orientado para a necessidade de suporte 24 horas em sete dias da semana; fundamental para a oferta de cursos online.

Um desafio na gestão de cursos a distância é possibilitar que o próprio aluno realize sua matrícula online em um ou mais cursos e consiga usar a plataforma de forma autônoma tanto quanto possível. Para esta questão, os três grupos adotaram a mesma estratégia. Elaboraram algum tipo de material como "tutorial para acesso Ilias" (Grupo Ilias) ou "manual de uso básico da plataforma [...] para auxiliar o acesso do aluno ao ambiente" e o "manuseio das diversas ferramentas de navegação oferecidas neste ambiente" (Grupo eFront). 
Os relatórios finais dos três grupos investigados revelam que a exploração das funcionalidades das plataformas teve por orientação as necessidades de uso para oferta dos cursos. Essa estratégia de aprendizagem, com participação ativa dos integrantes dos grupos, possui fundamentação destacadamente em Valente (2011), que defende abordagens educacionais que possibilitam a construção de conhecimento. Os estudantes se concentraram no que "necessitavam" aprender para atingir seu objetivo de oferecer cursos pela plataforma.

O relato dos grupos revelou que as plataformas apresentam grande similaridade quanto às suas funcionalidades: gerenciamento de backup; gestão de manutenção da plataforma; interface para administração de diversos perfis e acessos de usuários. Embora tenham relatado a presença destas funcionalidades, somente há registros de uso das opções de administração de perfis e acessos de usuários.

Registros nos relatórios finais dão conta do uso de várias opções de comunicação entre professor-aluno-aluno, entre elas chat, fórum, email e mensagens. O email se destacou como principal via de comunicação. Esse cenário sinaliza a preferência pela comunicação assíncrona, um dos argumentos utilizados pelos defensores da $\mathrm{EaD}$, pois permite a participação no processo educativo em tempos diferentes. A comunicação síncrona, importante para a solução de dúvidas em tempo real, foi pouco explorada.

Vale destacar a ocorrência de aprendizagem colaborativa, aluno-aluno para solução de dúvidas e dificuldades no uso das plataformas, denominado por Valente (2011, p. 31) como "redes de aprendizes", cuja interação possibilita a difusão do processo de aprendizagem.

Percebe-se, ao analisar os relatórios finais, que o grupo AVA Docebo destaca a atenção dada pelo grupo aos aspectos relativos ao conhecimento pedagógico ao declarar em seu relatório final que seu objeto de estudo relacionava-se com a análise da preparação das aulas, a metodologia de trabalho adotada, os recursos didáticos e a relação pedagógica na gestão de memoriais reflexivos sobre prática docente, apontando a importância da (re)escrita da experiência para o mencionado curso, traduzido em sentidos e significados atribuídos aos vários atores da $\mathrm{EaD}$.

O grupo eFront enfatizou o conhecimento tecnológico tanto pela distribuição das atividades da equipe coordenadora quanto pelo conteúdo do relatório final em que se destacaram aspectos da organização do tempo, da apropriação, configuração e uso de funcionalidades da plataforma, e até em um dos poucos registros em que se referiram a aspectos pedagógicos e de conteúdo a ênfase no aspecto tecnológico foi marcante.

O grupo Ilias dispensou especial atenção ao ponto de vista do aluno do curso. Enfatizou o controle e registro dos problemas enfrentados por seus alunos no acesso e uso da plataforma. Quanto ao acesso, identificou como causas a "antecipação ao cadastro na plataforma, que representou 18,18\% [...] e “"esquecimento' ou 'erro' na digitação do usuário e/ou senha, que representou 27,27\%"'. Quanto ao uso da plataforma, o grupo relatou que os problemas "foram atinentes à devoluta do próprio sistema quanto à postagem das atividades avaliativas [...] 36,36\% do total.", e também atividades de download de material didático assim relatadas "Os usuários que não conseguiram baixar o formulário que continha a segunda atividade avaliativa representou um total de $18,18 \%$ dos problemas diagnosticados." O grupo eFront sem detalhar estatisticamente apontou "acesso inicial ao curso" e "upload de arquivos" como as duas dificuldades de maior relevância por parte dos alunos. 


\section{Conclusão}

$\mathrm{Na}$ visão dos investigadores, enquanto observadores participantes, concluiu-se que esse trabalho propiciou o desenvolvimento de novos conhecimentos acerca da EaD e de ambientes virtuais de aprendizagem. A experiência de gestão de cursos online criou oportunidades para a construção de conhecimentos e o desenvolvimento de novas habilidades, tanto no que concerne ao conteúdo, quanto à prática pedagógica mediada pela tecnologia.

Percebeu-se que o uso das tecnologias da comunicação não muda, em princípio, as questões inerentes a qualquer projeto educativo. Há sempre que responder: para quem, para quê e como o projeto será desenvolvido. Quando se trata de cursos online ressaltase a importância de um projeto pedagógico consistente como base para o desenvolvimento dos cursos e a utilização de plataformas específicas para o gerenciamento da aprendizagem.

Ressalta-se a importância do planejamento da relação carga-horária e conteúdo a fim de se alcançar objetivos pedagógicos em um curso online, o que foi verificado nas análises dos grupos eFront e Ilias.

A equipe, que deve ter um olhar transdisciplinar na tríade proposta pelo TPACK, agindo de forma flexível e colaborativa deve procurar garantir a qualidade dos materiais e da aprendizagem dos alunos em curso. Este é um aspecto que se destaca desse trabalho investigativo. A observação participante e a análise dos dados revelaram diferenças marcantes no "olhar" e, portanto, nas ênfases que cada grupo atribuiu ao curso que ofertou.

O processo de ensino e de aprendizagem devem contextualizar a teoria e aproximá-la cada vez mais da realidade dos participantes. Ficou evidente a importância de continuar buscando o aperfeiçoamento da aprendizagem de todos os recursos e ferramentas oferecidas pelas plataformas, o que imputa uma maior dedicação para ampliar os conhecimentos acerca de todas as potencialidades, para oportunizar um maior aprendizado.

Considerando a concepção de curso online como premissa de trabalho, este estudo conclui que a tecnologia não determinou, nem limitou de modo significativo o trabalho de nenhum dos grupos. Ficou registrado que as plataformas investigadas atenderam às necessidades dos grupos, embora não tenha sido escopo do trabalho investigar limites de performance das plataformas, nem comparar exaustivamente suas funcionalidades. As indisponibilidades da conexão do ambiente dos servidores à Internet apontam a necessidade de atenção com a infraestrutura de TI, condições de contratação de conexão com a Internet e equipe de suporte dimensionada para atendimento conforme as exigências da modalidade dos cursos oferecidos.

A investigação conclui que o trabalho dos três grupos apresentou diferentes ênfases na articulação dos conhecimentos tecnológicos, pedagógicos e relativos ao conteúdo ministrado (Figura 2). Esta conclusão resulta de vários fatores, tais como, a organização funcional dos integrantes dos grupos, as atividades definidas por cada grupo nos cursos que ofertaram, a estratégia de comunicação, o objetivo definido por cada grupo, sendo que alguns se ocuparam mais com aspectos técnicos e outros com aspectos pedagógicos para a difusão dos conhecimentos propostos. Também a redação do relatório 
final parece ter sofrido influência da formação acadêmica e profissional dos integrantes, pois todo texto é elaborado a partir de um contexto.
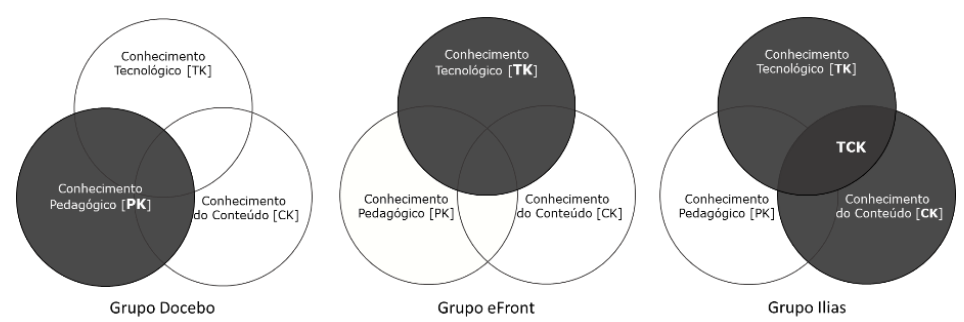

Figura 2. Ênfase na articulação de contextos

Fonte: Elaborado pelos autores

O relato do grupo AVA Docebo revelou ênfase no conhecimento pedagógico, focando principalmente na fundamentação do uso pedagógico das atividades e conteúdo do curso, demonstrando pouca ênfase nos aspectos tecnológicos da plataforma no relatório final. $\mathrm{O}$ grupo eFront mostrou que houve ênfase sobretudo no contexto tecnológico com alguma contribuição nos planos dos contextos conteúdo e pedagógico. Pode portanto o trabalho do grupo eFront ser caracterizado pela ênfase no conhecimento tecnológico. O relato do grupo Ilias, por sua vez, centrou-se na perspectiva da disseminação do conhecimento do conteúdo da plataforma, bem como no conhecimento tecnológico, ficando evidenciados aspectos do conhecimento do conteúdo.

Resta apontar a necessidade de estudos posteriores que investiguem quais fatores interferem na ênfase da articulação dos contextos definidos pelo modelo TPACK e em que medida isso ocorre em cursos a distância.

\section{Referências}

Alves, L. (2011). Educação a distância: conceitos e história no Brasil e no mundo. Revista Brasileira de Aprendizagem Aberta a Distância. São Paulo, v. 10, 2011. Recuperado em 07, agosto, 2014 de http://www.abed.org.br/revistacientifica/revista_pdf_doc/2011/artigo_07.pdf.

Bogdan, R.; Biklen, S. (1994). Investigação qualitativa em educação: uma introdução à teoria e aos métodos. Portugal: Porto Editora.

Brasileiro, A. M. M.(2013). Manual de Produção de Textos Acadêmicos e Científicos. São Paulo: Atlas.

Coutinho, C. P. (2011). TPACK: em busca de um referencial teórico para a formação de professores em tecnologia educativa. Revista Científica de Educação a Distância, v.2,n.4, jul, 2011. Recuperado em 17 outubro 2014 de http://repositorium.sdum.uminho.pt/handle/1822/13670.

Decreto $\mathrm{n}^{\mathrm{o}}$ 5.622, de 19 de dezembro de 2005. (2005, 19 de dezembro). Regulamenta o art. 80 da Lei 9.394, de 20 de dezembro de 1996, que estabelece as diretrizes e bases da educação nacional. Presidência da República. Brasília. Recuperado em 07, agosto , $2014 \quad$ de http://www.planalto.gov.br/ccivil_03/_Ato20042006/2005/Decreto/D5622.htm. 
CBIE-LACLO 2015

Anais do XXI Workshop de Informática na Escola (WIE 2015)

Decreto 5.800 de 08 de junho de 2006. Dispõe sobre o Sistema Universidade Aberta do Brasil - UAB. Presidência da República. Recuperado em 20 abril 2015 de http://www.planalto.gov.br/ccivil_03/_ato2004-2006/2006/decreto/d5800.htm.

Decreto 6.303 de 12 de dezembro de 2007. (2007, 12 de dezembro).Altera dispositivos dos Decretos nos 5.622, de 19 de dezembro de 2005, que estabelece as diretrizes e bases da educação nacional, e 5.773, de 9 de maio de 2006, que dispõe sobre o exercício das funções de regulação, supervisão e avaliação de instituições de educação superior e cursos superiores de graduação e sequenciais no sistema federal de ensino. Presidência da República. Brasília. Recuperado em 20 de abril, 2015 dehttp://www.planalto.gov.br/ccivil_03/_Ato2007-2010/2007/decreto/D6303.htm

Diehl, A. A.; Tatim, D. C. (2006). Pesquisa em ciências sociais aplicadas. São Paulo: Pearson.

Gatti, B. A. (2002). A construção da pesquisa em educação no Brasil. v1. Brasília - DF: Editora Plano.

Lei n $^{\circ}$ 9.394, de 20 de dezembro de 1996. (1996, 20 de dezembro). Estabelece as diretrizes e bases da educação nacional. Presidência da República. Brasília. Recuperado em 07, agosto, 2014 de http://www.planalto.gov.br/ccivil_03/LEIS/L9394.htm\#art80.

Marconi, M. A.; Lakatos, E. M. (2009). Fundamentos de metodologia científica. (6 ${ }^{\text {a }}$ ed.) São Paulo: Atlas.

Marinho, S. P. P. (2006). Novas tecnologias e velhos currículos; já é hora de sincronizar. Revista e-curriculum. v.2, n.1. Recuperado em 08 de setembro, 2014 de http://www.pucsp.br/ecurriculum.

Marinho, S. P. P. et al. (2014). APP currículo, escola e mobilidade. In: XXV Simpósio Brasileiro de Informática na Educação, 2014b, Dourados-MS, Anais... Workshops Congresso Brasileiro de Informática na Educação. Recuperado em 29 de janeiro, 2014 de http://www.br-ie.org/pub/index.php/wcbie/article/view/3234.

Mishra, P.; Koehler, M. J. (2006). Technological Pedagogical Content Knowledge: A new framework for teacher knowledge. Teachers College Record, v.108, n. 6, p. 10171054. Recuperado em 20 de agosto, 2014 de http://www.tcrecord.org/content.asp?contentid=12516.

Schulman, L. S. (1986). Those who understand: Knowledge growth in teaching. Educational Researcher, 15(2), 414.

Silva, M. (2010). Sala de aula interativa: educação, comunicação, mídia clássica, internet, tecnologias digitais, arte, mercado, sociedade, cidadania. 5. ed. Rio de Janeiro: Edições Loyola, 269 p. (Coleção práticas pedagógicas).

Valente, J. A. (2011). Educação a distância: criando abordagens educacionais que possibilitam a construção de conhecimento. p. 13-42, In: Arantes, V. A. (Org.). (2011). Educação a distância: pontos e contrapontos. São Paulo: Summus, (coleção pontos e contrapontos).

Vilaça, M. L. C. (2010). Educação a distância e tecnologias: conceitos, termos e um pouco de história. Revista Magistro, v. 1, n. 2. Duque de Caxias. Recuperado em 07, agosto 2014http://publicacoes.unigranrio.edu.br/index.php/magistro/article/view/1197. 